\title{
Preoperative hydronephrosis and diabetes mellitus predict poor prognosis in upper urinary tract urothelial carcinoma
}

\author{
Insang Hwang, MD; Seung II Jung, MD, PhD; Deok-Hyun Nam, MD; Eu Chang Hwang, MD; \\ Taek Won Kang, MD; Dong Deuk Kwon, MD; Soo Bang Ryu, MD
}

Department of Urology, Chonnam National University Medical School, Gwangiu, Republic of Korea

Cite as: Can Urol Assoc J2013;7:E215-20. http://dx.doi.org/10.5489/cuaj.11236. Epub 2012 July 16 .

\section{Abstract}

Introduction: We assess the impact of traditional prognostic factors, tumour location, degree of hydronephrosis and diabetes mellitus (DM) on the survival of patients treated for upper urinary tract urothelial carcinoma (UUTUC).

Methods: From January 2004 to March 2010, we analyzed data from 114 patients with UUTUC who underwent nephroureterectomy with a bladder cuff excision. Median patient age was 71 years and median follow-up was 26.5 months. The influence of traditional prognostic factors, including DM, tumour stage, grade, location and degree of hydronephrosis, on recurrence-free survival (RFS) rates were analyzed using Kaplan-Meier analysis and Cox proportional hazards regression model.

Results: Among 61 renal pelvis and 53 ureteral tumour cases, recurrence was identified in 71 cases $(62.3 \%)$. Kaplan-Meier analysis showed that degree of hydronephrosis was associated with RFS $(p=0.001)$. DM and degree of hydronephrosis were independent factors for RFS in Cox proportional regression analysis $(\mathrm{HR}=1.8 \mathrm{Cl}$ : 1.01-3.55, $p=0.04)$, (HR=3.7, Cl: 2.0-6.5, $p=0.001)$. All patients with ureteral tumour had no worse prognosis than those with renal pelvis tumour, but the PT2 patients with ureteral tumour had a worse prognosis than those with renal pelvis tumour with a median RFS of 9 months (range: 2.6-15.3 months) and 29 months (range: 8.0-13.2 months), respectively ( $p=0.028)$.

Conclusions: Tumour location is not a factor influencing RFS, except in the pT2 stage. However, severe hydronephrosis is associated with a higher recurrence in UUTUC. Also, DM is related to disease recurrence. Further prospective studies are needed to establish the prognostic significance of DM in large populations.

\section{Introduction}

Upper urinary tract urothelial carcinoma (UUTUC), including renal pelvic and ureteral cancer, is relatively rare, constituting $5 \%$ of all urinary tract urothelial carcinoma cases. ${ }^{1}$
Urothelial carcinoma of the renal pelvis is 3 to 4 times more common than ureteral urothelial carcinoma. ${ }^{2,3}$

$\mathrm{T}$ stage, tumour grade and lymphovascular invasion are thought to be prognostic factors for UUTUC. ${ }^{4-7}$ Of these factors, the most important is the pathologic T stage. Although computed tomography $(\mathrm{CT})$ has been applied to determine the preoperative $T$ stage in UUTUC, the accuracy of this prediction is poor, making it difficult to predict the prognosis of patients with UUTUC. ${ }^{8}$

The impact of tumour localization on prognosis has been debated. 6,9,10 In some reports, ureteral urothelial carcinoma had a worse prognosis than renal pelvic urothelial carcinoma. ${ }^{10-12}$ Generally, ureteral urothelial carcinoma causes gradual ureteral obstruction, resulting in hydronephrosis. This continuous obstruction may cause higher hydronephrosis grade and impairment of renal function. Therefore, severe degree of hydronephrosis may be associated with late detection of UUTUC and late treatment.

Diabetes mellitus (DM) is a chronic metabolic disease. Evidence indicates that DM is influential in the treatment outcomes of malignancies. ${ }^{13}$ Several studies have proposed an epidemiological association between DM and bladder urothelial cancer. ${ }^{13,14}$ Indeed, if DM and urothelial carcinoma risk are associated, it can be hypothesized that DM may influence the recurrence or progression of UUTUC. However, little has been reported concerning the relationship between DM and recurrence or progression of UUTUC.

To assess whether the grade of preoperative hydronephrosis and DM correlates with the prognosis of patients treated surgically for UUTUC, we retrospectively reviewed our single centre experience.

\section{Methods}

We retrospectively reviewed consecutive patients who had been surgically treated for UUTUC at our hospital from January 2004 to March 2010. We excluded distant metas- 
tasis at diagnosis, unresectable disease and concomitant invasive bladder cancer.

A study population of 114 patients was identified. Of these patients, $88(77.2 \%)$ were men and $26(22.8 \%)$ were women. The median patient age was 71 years (range: 41 to 84 ), and the median follow-up was 26.5 months (range: 23.5 to 31$)$.

All patients had undergone nephroureterectomy with bladder cuff excision. The patient follow-up protocol was relatively uniform and included surveillance cystoscopy, urinary cytology, abdominal-pelvic CT scan and chest radiography. These tests were performed at 3-month intervals for the initial 2 years, 6-month intervals for the next 2 years, and annually thereafter. Clinical information was obtained by retrospective review of all patient medical records, including DM. The hydronephrosis grade was assessed by preoperative imaging, $\mathrm{CT}$, excretory urography and renal ultrasonography. The cases without caliceal or pelvic dilation were classified as grade 0 hydronephrosis, tumours with pelvic dilation only were classified as grade 1 , and the cases accompanying mild calix dilation were classified as grade 2 . Tumours with severe calix dilation were grade 3 , and those with calix dilation accompanied by renal parenchyma atrophy were classified as grade 4 . Mild, moderate and severe hydronephrosis were classified as grade 1 , grade 2 and grade $3-4$, respectively.

The T stage and tumour grade of each tumour was assessed according to the 2002 American Joint Committee on Cancer TNM staging system and the 1998 World Health Organization/International Society of Urologic Pathologists' classification of papillary urothelial neoplasms. ${ }^{15,16}$

The primary outcomes were hydronephrosis and tumour locations. Tumour locations were divided to renal pelvis and ureter. Secondary outcomes were traditional prognostic factors with DM. Traditional prognostic factors included age, gender, tumour staging, tumour grade and perioperative chemotherapy status.

Disease recurrence was categorized as none, local recurrence, distant metastasis and bladder recurrence. Local recurrence was defined as any recurrence occurring in the tumour bed and regional lymph node. Bladder recurrence was defined as any documented recurrence in the bladder.

The Chi-square test and Student's t-test were used to compare percent frequencies. Postoperative survival was estimated using the Kaplan-Meier method and compared among groups with the log-rank test. Univariate and multivariate analysis were performed using Cox proportional hazards regression model. SPSS, version 17.0 (SAS Institute, Cary, NC) was used for statistical analysis. Two-sided $p$ values $<0.05$ were considered significant.

\section{Results}

Among the 61 renal pelvis and 53 ureteral tumour cases, recurrence was identified in 71 cases $(62.3 \%)$ (Table 1$)$. Eighteen patients had DM. From the imaging studies, 67 patients $(58.8 \%)$ presented with hydronephrosis. The number of mild (grade 1), moderate (grade 2) and severe (grade 3 and 4) hydronephrosis in renal pelvis tumour was 11 $(18.0 \%), 4(6.65 \%)$ and $7(11.5 \%)$, respectively. The number of mild (grade 1), moderate (grade 2 ) and severe (grade 3 and 4) hydronephrosis in ureter tumours was 19 (35.85\%), $13(24.5 \%)$ and $13(24.5 \%)$, respectively. The number of hydronephrosis in ureter tumour was higher than for renal pelvis tumour $(p=0.0001)$. Of the 20 patients with severe

\begin{tabular}{|c|c|c|c|c|}
\hline \multicolumn{5}{|c|}{ Median (range) or $\mathbf{n}(\%)$} \\
\hline & Total $n=114$ & $\begin{array}{c}\text { Renal } \\
\text { pelvis } n=61\end{array}$ & Ureter $n=53$ & $p$ value \\
\hline Age & $71.0(44-84)$ & $\begin{array}{c}71.0(47- \\
84)\end{array}$ & $71.0(44-81)$ & $0.917^{*}$ \\
\hline M:F & $88: 26$ & $50: 11$ & $38: 15$ & $0.192^{\dagger}$ \\
\hline DM & $18(15.8)$ & $13(21.3)$ & $5(9.4)$ & $0.083^{\dagger}$ \\
\hline \multicolumn{5}{|l|}{ Hydronephrosis } \\
\hline None & $47(41.2)$ & $39(63.9)$ & $8(15.1)$ & \multirow{4}{*}{$0.0001^{\dagger}$} \\
\hline Mild & $30(26.3)$ & $11(18.0)$ & $19(35.8)$ & \\
\hline Moderate & $17(14.9)$ & $4(6.6)$ & $13(24.5)$ & \\
\hline Severe & $20(17.5)$ & $7(11.5)$ & $13(24.5)$ & \\
\hline \multicolumn{5}{|l|}{ pT stage } \\
\hline $\mathrm{Ta}$ & $22(19.3)$ & $13(21.3)$ & $9(17.0)$ & \multirow{4}{*}{$0.062^{\dagger}$} \\
\hline T1 & $23(20.2)$ & $15(24.6)$ & $8(15.1)$ & \\
\hline $\mathrm{T} 2$ & $26(22.8)$ & $8(13.1)$ & $18(34.0)$ & \\
\hline T3 & $43(37.7)$ & $25(41.0)$ & $18(34.0)$ & \\
\hline \multicolumn{5}{|l|}{ Grade } \\
\hline Low & $31(27.2)$ & $16(26.2)$ & $15(28.3)$ & \multirow{2}{*}{$0.804^{\dagger}$} \\
\hline High & $83(72.8)$ & $45(73.8)$ & 38 (71.7) & \\
\hline \multicolumn{5}{|l|}{$\begin{array}{l}\text { Adjuvant } \\
\text { treatment }\end{array}$} \\
\hline None & $56(49.1)$ & $31(50.8)$ & $25(47.2)$ & \multirow{4}{*}{$0.498^{\dagger}$} \\
\hline Chemotherapy & $56(49.1)$ & $30(49.2)$ & $26(49.1)$ & \\
\hline Radiotherapy & $1(0.9)$ & $0(0)$ & $1(1.9)$ & \\
\hline $\begin{array}{l}\text { Chemo- } \\
\text { radiotherapy }\end{array}$ & $1(0.9)$ & $0(0)$ & $1(1.9)$ & \\
\hline \multicolumn{5}{|l|}{$\begin{array}{l}\text { Type of } \\
\text { recurrence }\end{array}$} \\
\hline None & $43(37.7)$ & $25(41.0)$ & $18(34.0)$ & \multirow{4}{*}{$0.348^{\dagger}$} \\
\hline $\begin{array}{l}\text { Local } \\
\text { recurrence }\end{array}$ & $13(11.4)$ & $4(6.6)$ & $9(17.0)$ & \\
\hline $\begin{array}{l}\text { Distant } \\
\text { metastasis }\end{array}$ & $12(10.5)$ & $6(9.8)$ & $6(11.3)$ & \\
\hline $\begin{array}{l}\text { Bladder } \\
\text { recurrence }\end{array}$ & $46(40.4)$ & $26(42.6)$ & $20(37.7)$ & \\
\hline
\end{tabular}


Prognostic factors in upper urothelial carcinoma

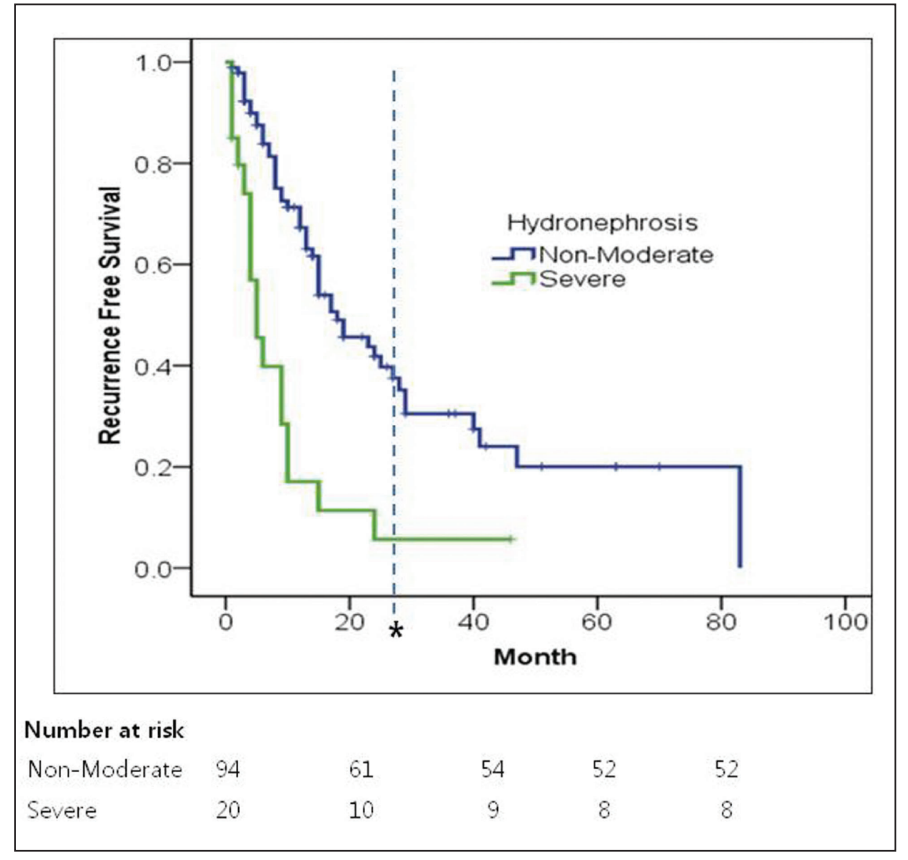

Fig. 1. Kaplan-Meier estimates for recurrence-free survival in 114 patients treated with nephroureterectomy for upper tract urethelial tumour stratified by the presence of preoperative severe hydronephrosis ( ${ }^{*}$ Number at risk at median follow-up; Non-Moderate: 32, Severe: 9).

hydronephrosis (grade 3 or 4 ), 13 patients (65\%) had invasive UUTUC ( $\geq T 2$ stage).

Kaplan-Meier analysis showed that severe hydronephrosis was associated with lower recurrence free survival (RFS) compared to non-moderate hydronephrosis (log rank $p=0.001$ ) (Table 2, Fig. 1).

Overall, patients with ureter tumours did not have a worse prognosis than those with renal pelvis tumours. However, in the T2 stage, patients with ureter tumours had worse RFS (9 months; range: 2.6-15.3) than those with renal pelvis tumours (29 months; range: 8.0-13.2) ( $p=0.028)$ (Table 3, Fig. 2).

In Cox proportional regression analysis, DM and degree of hydronephrosis were independent prognostic factors for tumour recurrence (hazard ratio [HR] 1.8, 95\% confidence interval $[\mathrm{Cl}]$ : 1.01-3.55, $p=0.04$; HR 3.7, 95\%Cl: 2.0-6.5, $p=0.001$ ], respectively (Table 4, Fig. 3).

Above the T3 stage, 20 of 25 patients $(80 \%)$ with renal pelvis tumours and 15 of 18 patients (83\%) with ureteral tumours received adjuvant chemotherapy. Below the T2 stage, only 10 of 36 patients $(27.8 \%)$ with renal pelvis tumours and 13 of 35 patients (37.1\%) with ureteral tumours received adjuvant chemotherapy or radiation therapy. Of the below T2 stage patients receiving adjuvant treatment, only 6 of 10 patients with renal pelvis tumours and 5 of 13 patients with ureteral tumours were immediately treated with postoperative chemotherapy.

\section{Discussion}

UUTUC represents a few urothelial carcinomas in the urinary system. T stage, tumour grade, lymph node invasion, lymphovascular invasion and DNA ploidy are prognostic factors for UUTUC. ${ }^{4-7,9,10}$ However, because these prognostic factors are pathology-related, predicting the prognosis of UUTUC before surgery is not easy. In UUTUC cases, using CT scans to distinguish between stage Tis, T1 and T2 is impossible. ${ }^{17}$

In addition to traditional prognostic factors, such as tumour stage and grade, several studies suggest that ureteral tumours are associated with a poorer prognosis than renal pelvic tumours. ${ }^{10-12,18}$ However, other investigators reported conflicting results on the same issue. For example, one study reported that distal ureteral tumours showed significantly better survival than proximal ureteral or renal pelvic tumours. ${ }^{19}$ Meanwhile, another study reported no prognostic difference with respect to tumour location in upper urinary tract cases. ${ }^{20}$

Generally, ureteral tumours cause gradual ureteral obstruction that results in the development of hydronephrosis. The continuous obstruction causes a higher degree of obstruction and T stage. Several studies have reported that $60 \%$ to $81 \%$ of patients who presented with kidney non-

\begin{tabular}{|c|c|c|}
\hline \multirow{3}{*}{ Factors } & \multirow{2}{*}{\multicolumn{2}{|c|}{ Recurrence-free survival }} \\
\hline & & \\
\hline & Median month (95\%Cl) & $p$ value \\
\hline \multicolumn{3}{|l|}{ Age } \\
\hline$\leq 70$ & $15(9.2-20.7)$ & \multirow{2}{*}{0.473} \\
\hline$>70$ & 15 (116.-18.3) & \\
\hline \multicolumn{3}{|l|}{ Gender } \\
\hline Male & $15(11.3-18.6)$ & \multirow{2}{*}{0.519} \\
\hline Female & $12(3.4-20.5)$ & \\
\hline \multicolumn{3}{|l|}{ DM } \\
\hline Positive & $12(3.6-20.3)$ & \multirow{2}{*}{0.179} \\
\hline Negative & $15(10.5-19.4)$ & \\
\hline \multicolumn{3}{|l|}{ Location } \\
\hline Renal pelvis & $19(9.4-28.5)$ & \multirow{2}{*}{0.325} \\
\hline Ureter & $13(9.2-16.7)$ & \\
\hline \multicolumn{3}{|l|}{ pT stage } \\
\hline Ta-T1 & $15(2.9-27.0)$ & \multirow{2}{*}{0.18} \\
\hline T2-T3 & $15(10.7-19.2)$ & \\
\hline \multicolumn{3}{|l|}{ Grade } \\
\hline Low & $15(9.4-20.5)$ & \multirow{2}{*}{0.527} \\
\hline High & $15(10.3-19.5)$ & \\
\hline \multicolumn{3}{|l|}{ Hydronephrosis } \\
\hline None-moderate & $18(12.1-23.8)$ & \multirow{2}{*}{0.001} \\
\hline Severe & $5(2.3-7.6)$ & \\
\hline Cl: confidence interval & abetes mellitus. & \\
\hline
\end{tabular}




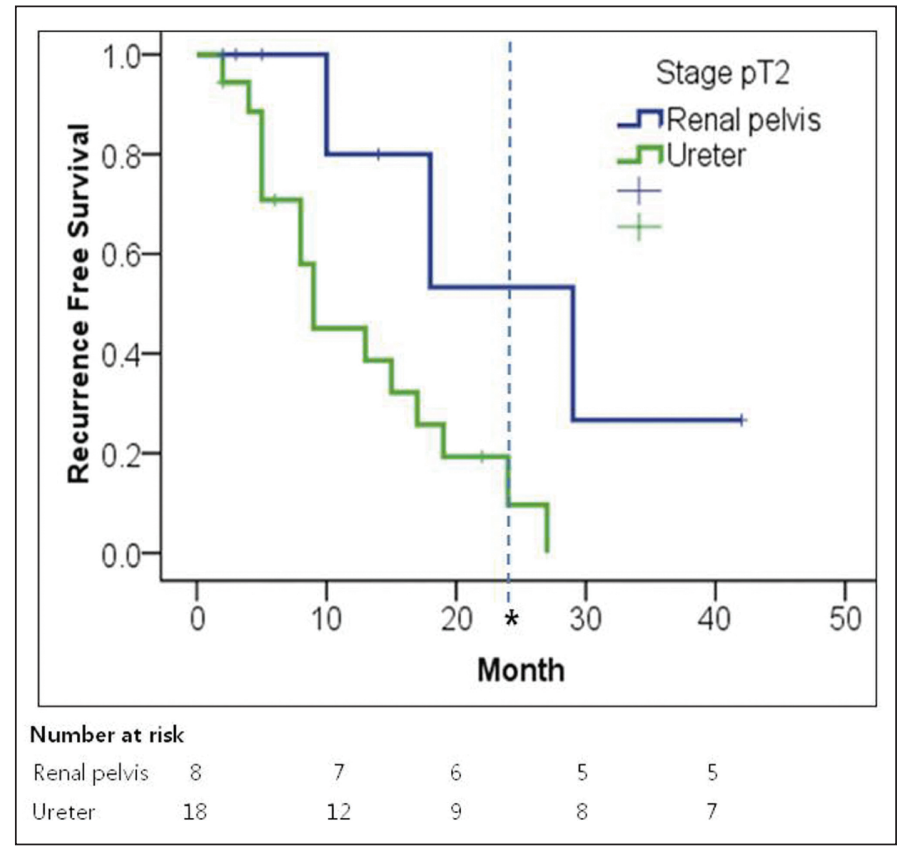

Fig. 2. Kaplan-Meier estimates for recurrence-free survival in stage T2 patients $(\mathrm{n}=26)$ treated with nephroureterectomy for upper tract urethelial tumour stratified by location of tumour (*Number at risk at median follow-up; Renal pelvis: 6, Ureter: 9).

visualization by excretory urography had invasive cancer. In addition, hydronephrosis also correlated with the T stage..$^{21,22}$

Presently, hydronephrosis and T stage did not correlate. Therefore, we investigated whether the anatomical location of urothelial carcinoma (renal pelvis vs. ureter) and degree of hydronephrosis has real prognostic value for UUTUC. In the present study, hydronephrosis had a significant influence on the RFS rate of patients with UUTUC. Our results indicate that tumour location is not a prognostic factor, except for T2 stage tumours.

Since ureteral tumours were more frequently associated with stage T2 or greater and hydronephrosis than renal pelvic tumours at diagnosis in our patient cohort, we performed stratification analysis to adjust for stage differences. We observed significant differences according to tumour location for stage T2. At stage T2, ureteral tumours were related to a significantly higher recurrence rate than renal pelvis tumours. These results might be explained by several reasons. The first reason is that $\mathrm{T} 2$ ureteral tumours may not protect the tumour from spreading as in renal pelvic tumours. Such results may be explained by the presence of a thin layer of adventitia surrounding the ureter, which contains an extensive plexus of ureteral vessels and lymphatics that makes tumour spreading easier. The other possible reason is that the renal parenchyma and perihilar adipose tissue surrounding the renal pelvis may act as a barrier against early spread. ${ }^{23,24}$ One study reported an overall better prognosis of renal pelvic tumour than ureteral tumour; the authors suggested the protective role of thick renal parenchyma against
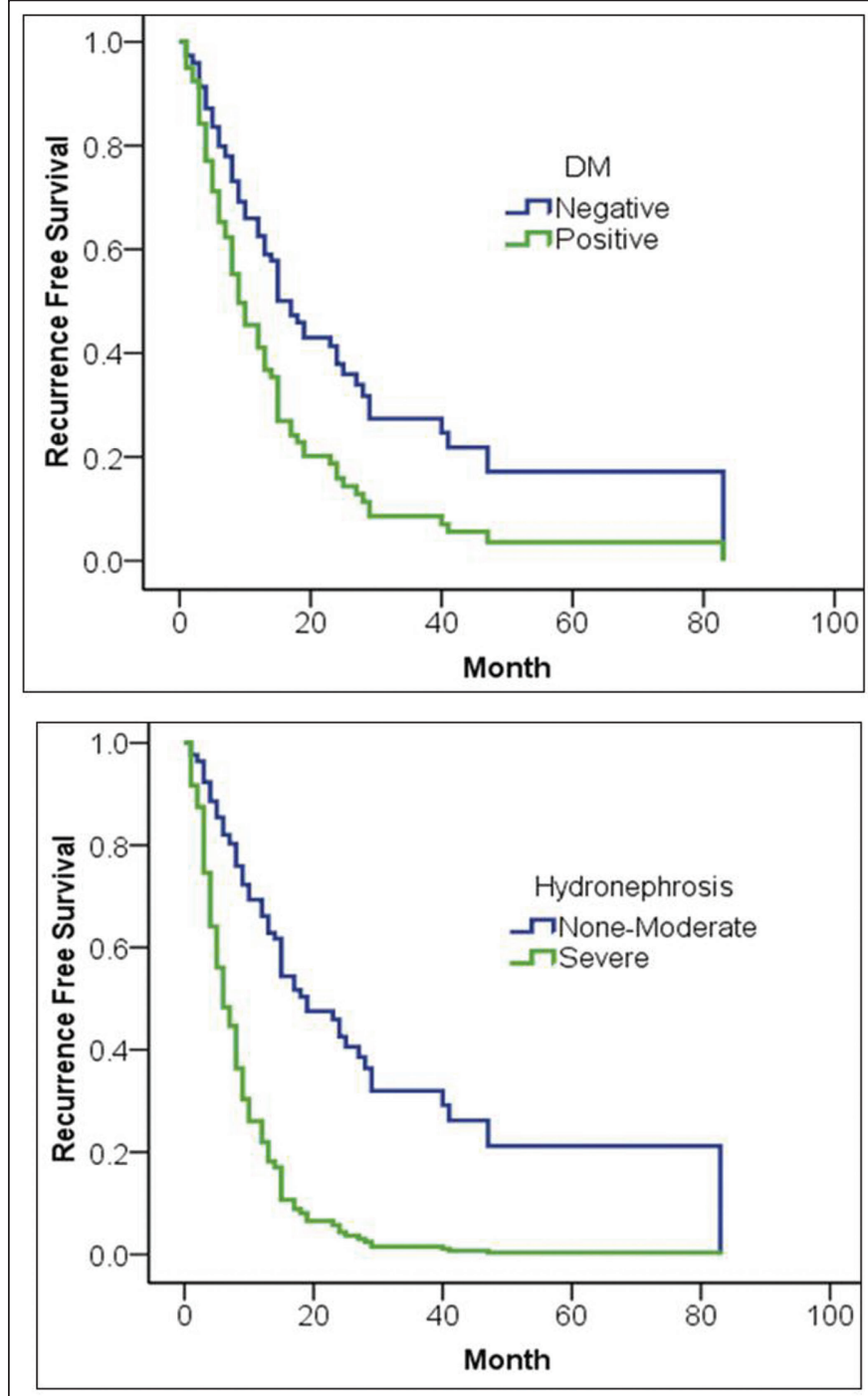

Fig. 3. Cox proportional hazard analysis of DM (A) and severe hydronephrosis (B) for recurrence-free survival in upper urinary tract urothelial carcinoma.

local tumour spread..$^{12}$ Another reason is adjuvant chemotherapy, which is usually undertaken in UUTUC above T2, according to the medical insurance policy in Korea. Patients with T2 stage urothelial carcinoma could not receive adjuvant chemotherapy. This might explain why the prognosis of T2 was poorer than T3 in ureteral tumours.

The overall prognosis according to tumour location was not different. It was mainly attributed to adjuvant chemotherapy in stage above T2. But, the preoperative degree of hydronephrosis has an important independent prognostic value. Our findings may explain institutional differences in the prognostic significance of UUTUC location. In some reports, ureteral tumour confers a worse prognosis than renal pelvis tumour. ${ }^{11,12}$ However, these reports had more T2 ureteral tumour patients that renal pelvis tumour $(24.4 \%$ vs. $4 \%$, and $22.5 \%$ vs. $6.5 \%$ ). When more T2 ureteral tumours were 


\begin{tabular}{|c|c|c|c|}
\hline & \multicolumn{2}{|c|}{$\begin{array}{l}\text { Recurrence-free survival (months, } \\
\qquad 95 \% \mathrm{Cl})\end{array}$} & \multirow[b]{2}{*}{$p$ value } \\
\hline & Renal pelvis & Ureter & \\
\hline \multicolumn{4}{|l|}{ pStage } \\
\hline $\mathrm{Ta}$ & - & $40(0-95.7)$ & 0.213 \\
\hline $\mathrm{T} 1$ & $6(0-14.2)$ & $10(2.6-17.3)$ & 0.55 \\
\hline $\mathrm{T} 2$ & $29(8.0-13.2)$ & $9(2.6-15.3)$ & 0.028 \\
\hline T3 & $15(4.18-25.8)$ & $15(9.0-20.9)$ & 0.699 \\
\hline \multicolumn{4}{|l|}{ Hydronephrosis } \\
\hline None-moderate & $25(13.9-36.0)$ & $15(11.0-18.9)$ & 0.38 \\
\hline Severe & $4(0.7-7.2)$ & $9(5.0-12.9)$ & 0.12 \\
\hline
\end{tabular}

included, the prognosis of overall ureteral tumour might be poorer.

The present study also indicates that DM is an independent prognostic factor for RFS. Epidemiologic studies of diabetes and risk of urothelial carcinoma have been inconsistent. Several cohort studies reported that diabetes is related with a statistically significant 1.3 to 2.5 -fold increased risk of bladder cancer. ${ }^{25-27}$ We suspect that DM is related with UUTUC. The mechanism by which DM contributes towards urothelial cancer remains uncertain. One suggested mechanism is that chronic exposure to hyperinsulinemia or hyperglycemia is a possible factor to induce tumour cell proliferation and metastasis. ${ }^{28,29}$ Another possible mechanism is a structural change in urothelium in diabetic nephropathy. Cadherins are a family of membrane glycoproteins involved in cell-to-cell adhesion. A study that looked at cadherin distribution and quantity in rat renal cells exposed to glycated proteins found a decrease in both cadherin amount and distribution. ${ }^{30}$ Reduced expression of the subtype E-cadherin has been associated with poor outcome in bladder cancer patients and has been shown to correlate with increased tumour invasion. ${ }^{13}$ Further investigations are warranted regarding structural changes of urothelium in patients with DM and UUTUC.

Our study had several limitations. Firstly, the follow-up period might not have been long enough; therefore, we could not evaluate cancer-specific survival. Secondly, the number of enrolled patients was small and the follow-up period was short in the group of renal pelvic tumour patients. Since we studied small size populations, the $95 \%$ confidence interval for the diabetic hazard ratio for RFS prognostic factors is just barely significant. Further investigations with large populations, including diabetes patients, will be needed to establish the prognostic significance of DM.

\begin{tabular}{lcc}
\hline $\begin{array}{l}\text { Table 4. Cox proportional hazard analysis of prognostic } \\
\text { factors for recurrence-free survival in upper urinary tract } \\
\text { transitional cell carcinoma }\end{array}$ & \multicolumn{2}{l}{ Recurrence-free survival } \\
\hline \multicolumn{3}{l}{ Hazard ratio } \\
Factors & $(\mathbf{9 5 \%} \% \mathbf{C l )}$ & p value \\
\hline DM & $1.8(1.01-3.55)$ & 0.04 \\
pStage (T2-T3) & $1.60(0.9-2.6)$ & 0.07 \\
Hydronephrosis (Severe) & $3.7(2.0-6.5)$ & 0.001 \\
\hline Cl: confidence interval; DM: diabetes mellitus. & \\
\hline
\end{tabular}

\section{Conclusions}

In patients with urothelial carcinoma, severe hydronephrosis is related to a greater risk of disease recurrence after nephroureterectomy. Also, DM is related to disease recurrence. Therefore, in patients with these factors, close follow-up is recommended. Further prospective studies are needed to establish the prognostic significance of DM in large populations.

In the present study, tumour location was not a prognostic factor, except for T2 ureteral tumours. We usually performed adjuvant chemotherapy for patients with upper urinary tract TCC stage above T2. But, the prognosis of T2 ureteral tumour is not good and differs from renal pelvis tumour, so adjuvant treatment and close follow-up should be considered.

Competing interests: None declared.

This paper has been peer-reviewed.

\section{References}

1. Tawfiek ER, Bagley DH. Upper-tract transitional cell carcinoma. Urology 1997;50:321-9. htrp://dx.doi. org/10.1016/50090-4295(97)00230-6

2. Huben RP, Mounzer AM, Murphy GP. Tumour grade and stage as prognostic variables in upper tract urothelial tumour s. Cancer 1988;62:2016-20. http://dx.doi.org/10.1002/10970142(19881101)62:9<2016::AID-CNCR2820620924>3.0.C0;2-6

3. Murphy DM, Zincke H, Furlow WL. Primary grade 1 transitional cell carcinoma of the renal pelvis and ureter. J Urol 1980;123:629-31.

4. Cozad SC, Smalley SR, Austenfeld M, et al. Transitional cell carcinoma of the renal pelvis or ureter: patterns of failure. Urology 1995;46:796-800. htrtp://dx.doi.org/10.1016/S0090-4295(99)80346-X

5. Hong B, Park S, Hong JH, et al. Prognostic value of lymphovascular invasion in transitional cell carcinoma of upper urinary tract. Urology 2005;65:692-6. http://dx.doi.org/10.1016/i.urology.2004.11.001

6. Corrado F, Ferri C, Mannini D, et al. Transitional cell carcinoma of the upper urinary tract: evaluation of prognostic factors by histopathology and flow cytometric analysis. J Urol, 1991;145:1159-63.

7. Kikuchi E, Horiguchi Y, Nakashima J, et al. Lymphovascular invasion independently predicts increased disease specific survival in patients with transitional cell carcinoma of the upper urinary tract. J Urol, 2005;174:2120-3; discussion 2124. http://dx.doi.org/10.1097/01.ju.0000181801.22474.8b

8. Scolieri MJ, Paik ML, Brown SL, et al. Limitations of computed tomography in the preoperative staging of upper tract urothelial carcinoma. Urology 2000;56:930-4. http://dx.doi.org/10.1016/500904295(00)00800-1

9. Hall MC, Womack S, Sagalowsky Al, et al. Prognostic factors, recurrence, and survival in transitional cell carcinoma of the upper urinary tract: a 30-year experience in 252 patients. Urology 1998;52:594-601. http://dx.doi.org/10.1016/50090-4295(98)00295-7 
Hwang et al.

10. Ozsahin M, Zouhair A, Villa S, et al. Prognostic factors in urothelial renal pelvis and ureter tumours: a multicentre Rare Cancer Network study. Eur J Cancer 1999;35:738-43. http://dx.doi.org/10.1016/ S0959-8049(99)00012-X

11. Park S, Hong B, Kim CS, et al. The impact of tumour location on prognosis of transitional cell carcinoma of the upper urinary tract. J Urol 2004;171:621-5. http://dx.doi.org/10.1097/01. ju.0000107767.56680.f7

12. Park J, Ha SH, Min GE, et al. The protective role of renal parenchyma as a barrier to local tumour spread of upper tract transitional cell carcinoma and its impact on patient survival. J Urol 2009;182:894-9. http://dx.doi.org/10.1016/i.juro.2009.05.040

13. Hwang EC, Kim YJ, Hwang IS, et al. Impact of diabetes mellitus on recurrence and progression in patients with non-muscle invasive bladder carcinoma: A retrospective cohort study. Int J Urol 2011. http://dx.doi. org/10.1111/.1.1442-2042.2011.02845.x

14. Larsson SC, Andersson SO, Johansson JE, et al. Diabetes mellitus, body size and bladder cancer risk in a prospective study of Swedish men. Eur J Cancer 2008;44:2655-60. http://dx.doi.org/10.1016/j. eica.2008.07.012

15. Epstein Jl, Amin MB, Reuter VR, et al. The World Health Organization/International Society of Urological Pathology consensus classification of urothelial (transitional cell) neoplasms of the urinary bladder. Bladder Consensus Conference Committee. Am J Surg Pathol 1998;22:1435-48. http://dx.doi. org/10.1097/00000478-199812000-00001

16. Greene FL, Page DL, Fleming ID, et al. AJCC cancer staging manual. 6th ed. Vol. 1. 2002, New York: Springer Verlag.

17. Planz B, George R, Adam G, et al. Computed tomography for detection and staging of transitional cell carcinoma of the upper urinary tract. Eur Urol 1995;27:146-50.

18. Akdogan B, Dogan HS, Eskicorapci SY, et al. Prognostic significance of bladder tumour history and tumour location in upper tract transitional cell carcinoma. J Urol 2006;176:48-52. htrp://dx.doi.org/10.1016/ S0022-5347(06)00511-8

19. van der Poel $\mathrm{HG}$, Antonini $\mathrm{N}$, van Tinteren $\mathrm{H}$, et al. Upper urinary tract cancer: location is correlated with prognosis. Eur Urol 2005;48:438-44. http://dx.doi.org/10.1016/.i.eururo.2005.03.009
20. Catto JW, Yates DR, Rehman I, et al. Behavior of urothelial carcinoma with respect to anatomical location. J Urol 2007; 177:1715-20. http://dx.doi.org/10.1016/i.juro.2007.01.030

21. McCarron JP, Mills C, Vaughn ED Jr. Tumours of the renal pelvis and ureter: current concepts and management. Semin Urol 1983; 1:75-81.

22. Chung $\mathrm{HJ}$, Chen KK, Lin AT, et al. Is renal function at the tumour side a prognostic factor in ureteral transitional cell carcinoma? Urol Int 1997;59:166-9. htrp://dx.doi.org/10.1159/000283054

23. Yang JM, Huang WC. Bladder wall thickness on ultrasonographic cystourethrography: affecting factors and their implications. J Ultrasound Med 2003;22:777-82.

24. Miyake $\mathrm{H}$, Hara I, Gohii K, et al. The significance of lymphadenectomy in transitional cell carcinoma of the upper urinary tract. Br J Urol 1998;82:494-8. http://dx.doi.org/10.1046/i.1464-410X.1998.00800.x

25. Tripathi A, Folsom AR, Anderson KE. Risk factors for urinary bladder carcinoma in postmenopausal women. The lowa Women's Health Study. Cancer 2002;95:2316-23. http://dx.doi.org/10.1002/cncr.10975

26. Coughlin SS, Calle EE, Teras LR, et al. Diabetes mellitus as a predictor of cancer mortality in a large cohort of US adults. Am J Epidemiol 2004;159:1160-7. http://dx.doi.org/10.1093/aje/kwh161

27. Jee SH, Ohrr H, Sull JW, et al. Fasting serum glucose level and cancer risk in Korean men and women. JAMA 2005;293:194-202. http://dx.doi.org/10.1001/jama.293.2.194

28. Richardson LC, Pollack LA. Therapy insight: Influence of type 2 diabetes on the development, treatment and outcomes of cancer. Nat Clin Pract Oncol 2005;2:48-53. http://dx.doi.org/10.1038/ncponc0062

29. Attia N, Caprio S, Jones TW, et al. Changes in free insulin-like growth factor-1 and leptin concentrations during acute metabolic decompensation in insulin withdrawn patients with type 1 diabetes. I Clin Endocrinol Metab 1999;84:2324-8. hitp://dx.doi.org/10.1210/ic.84.7.2324

30. Singh AK, Mo W, Dunea $G$, et al. Effect of glycated proteins on the matrix of glomerular epithelial cells. J Am Soc Nephrol 1998;9:802-10.

Correspondence: Dr. Seung II Jung, Department of Urology, Chonnam National University Medical School, 8, Hak-dong, Dong-gu, Gwangju 501-757, Republic of Korea; fax: +82-62-227-1643; drisi@yahoo.co.kr 